\title{
Establishing Linkages between Intelligence, Emotional and Spiritual Quotient on Employees Performance in Government Sector of Pakistan
}

\author{
Arshad Mahmood ${ }^{1}$ \\ Mohd Anuar Arshad² \\ Adeel Ahmed ${ }^{3}$ \\ Sohail Akhtar ${ }^{4}$ \\ Zain Rafique 5 \\ ${ }^{1234}$ School of Management, Universiti Sains Malaysia \\ 3University of Turbat, Pakistan \\ Doi:10.5901/mjss.2015.v6n6s2p553 \\ ${ }^{5}$ School of Social Science, Univeristi Sains Malaysia

\section{Abstract} \\ This paper aims to investigate the effect of IQ (intelligence quotient) EQ (emotional quotient) and SQ (spiritual quotient) on \\ employee performance in government sector of Pakistan This study adopted Spiritual Intelligence Self-Report Inventory (SISRI) \\ by D. King., Emotional quotient scale by Reuven Bar-On, Intelligent quotient factor analysis by Adrian Furnham, Religion \\ Personality Index (MRPI) by Azimi Hamzah and Measurements of performance by Sarmiento, Beale \& Knowles (2007). The \\ data was collected from ministry, administration and directorates of Pakistan. The study administered and received all the 347 \\ completed set of questionnaires (259 employees of grade 1-13, 72 employees of grade 14-18 and 16 employees of grade 19- \\ 22). SEM result of $I Q, E Q$ and $S Q$ shows that they have the significant and positive correlation with the performance of \\ employees. $S Q$ improves performance if the trainings regarding it are provided. Functions of Religion as a moderator in \\ employee job performance. This research has extended knowledge in the workplace with SQ confirm that SQ is more important \\ than the $E Q$ and IQ in influencing the employee performance. The empirical findings of the study shows that organizations may \\ formulate strategies and policies to improve performance of employees by encouraging and allowing the activities of spiritual \\ quotient in the workplace, regardless of religion and spiritual beliefs, and thus facilitate the mutual understanding and respect. \\ This is the only study that measured the impact of $I Q, E Q$ and $S Q$ on employee's performance with religion as a moderator.
}

Keywords: Intelligence quotient, Emotional quotient, Spiritual quotient, Religion, Performance, Pakistan, employees

\section{Introduction}

\subsection{Background of the study}

It is generally noted that people spend most of their time at work place and in work-related social and leisure activities to compartmentalize their lives into the domains such as work types, family and religion (Osman et al, 2013, Klerk, 2005). Anyhow, majority of employees search for meaning in their work (Brannan 2015), but due to constraints in time and knowledge, they are not able to fulfill their spiritual, intelligence and emotional needs. The concepts of spiritual and emotional needs are interrelated with humanistic environment (Garcia, 2003). To cope with this, a number of organizations provide humanistic environment to its employees as it is in the benefit of both the employees and the employers but they have not yet succeeded due to the paucity of available guidance and dearth of literature about Intelligence Quotient, Emotional Quotient and Spiritual Quotient (hereafter, IQ, EQ and SQ). Nevertheless, organizations always encourage this new trend.

A rising base of literature suggests that there are significant effects of IQ, EQ and SQ on employee's behavior generally and employee's performance specifically (Upadhyay 2015). In addition, religion also has a positive effect on employee's performance especially in decision making (Azimi, 2007; Noronha 2015). Despite this, there exists a research gap linking IQ, EQ and SQ on employee performance in developing countries like Pakistan as there is no single study available in this context (Asrar-ul-Haq, 2014). Scholars such as Osman (2013) and King (2010) agree that this area specifically lacks empirical research.

Hence, the present paper is much needed empirical research to establish the linkages among IQ, EQ and SQ on employee performance while using religion as a moderator by taking government sector of Pakistan as our case-study. 


\section{Review of Literature}

\subsection{Intelligence Quotient}

The concept of IQ was given by William Stern in 1912 and is considered as the primary step of organization's performance as it includes the creativity of mind (Pan, 2006). IQ is the ability to think rationally, recall, learn, understand, solving the problem and then effectively implementing what one has learnt (Bell, 2014). IQ leads an organization towards better effective and efficient performance (Kilic 2013).

Gardner (1983), author of the 'theory of multiple intelligences', concurs, suggesting that the IQ movement is blindly empirical with little concern for the processes involved in intelligence tests. He further describes the IQ test as "the 'shotgun' approach to the assessment of human intellect" (Gardner, 1983, p. 18), noting that tests are usually unrelated to everyday life.

\subsection{Emotional Quotient}

$\mathrm{EQ}$ is knack to understand, sense and then the application of these emotions as the base for influence, connection, information and human energy (Johar, 2013). EQ is our ability to recognize emotions and feelings to motivate ourselves and then manage it in ourselves and dealing with others. According to Brooks (2006) emotional conditions are used as personal feelings to achieve, motivate and plain performance in an organization. Furthermore, Goleman et al. (2002) while examining the affect of emotions on the performance of organization finds that $\mathrm{EQ}$ helps in reducing the conflict in organization and resultantly increase the employees' performance. The success and failure of an organization can be determined by the emotional tone set by the executive interpersonal.

\subsection{Spiritual Quotient}

SQ is also called as the ultimate intelligence by Zohar and Marshall (2000), who place it at the top of a hierarchy, with EQ and IQ below it. The SQ of employees in an organization has silent but effective role on employee's performance. SQ is the ability to kill the ego before it kills the creativity and helps the employees to make their work more meaningful and ensue (George 2006). The need of SQ in organizations is to make employees whole, makes their work pre culture meaningful and SQ is the ability to kill the ego (George 2006). According to Zohar \& Marshal (2004), SQ acknowledges us to know what we and our organizations are about. SQ gives purpose and meaning to life and allows us to build new possibilities. SQ acknowledges us to develop our 'IQ and EQ' in a united way to express our talent in the world. It helps not only to better our own lives but also other human beings (Mishra, 2014). It gives us a deep sense of knowing or of discovering the deepness or significance of things. (Zohar \& Marshal 2000). The practices of SQ in an organization have the positive effect on employee's performance (karakas 2009). The existence of SQ in the organization will better creates self awareness, behavior, judgment of self-control, decision power, flexibility, adaptability, vision, consciousness, value, sense, and intuition of the employee. Therefore, SQ helps employee to evolve towards betterment of the organization (Zohar \& Marshal, 2004; 2012). SQ will make the employees connected to the organization, making their work more meaningful and helps to lowered down personal ego via self reflection. These in turn will enhance individual potential and organizational performance. (George, 2006; Paloutzian, Emmons, \& Keortge, 2003; Froidevaux, \& Hirschi, 2015). Thus, SQ provides a basis for a kind of meta-strategic thinking strategic thinking that can stand back from and assess strategies themselves.

\subsection{Religion}

Religion is an organized and structural system of beliefs that gives meaning and sense to life. Religion gives the right way and generates self-control in humans. Religion is not only the set of beliefs but also guide to practice them in daily life. (2 citations)

Since, 97\% population of Pakistan is Muslim and Islam being the most dominant religion, (Act 1973, Rafique \& Anwar, 2014) religion in the present paper would be considered as Islam. Islam provides guidance for all aspects of human life, although some indication of a general nature.

Islam as a doctrine has contributed a lot to develop IQ EQ SQ in humans. The holy book Qur'an clearly positions the spiritual quotient as the part of the strategy to pure the heart. Islamic teachings and values are applicable in any situation place and time on Muslims as Islam has the strong concept of reward and punishment after death (Azimi 2007). 
Hence, it can be clearly articulated that religion, Islam would affect the performance of an employee in an organization.

\subsection{Performance}

The applications of IQ, EQ and SQ can be used as an effective tool to increase the employees' performance. Arguably, employees are not only satisfied with compensation, rewards and benefits but they also need the utmost respect in organization and friendly-interaction with employees and managers. Therefore, Spiritual, Emotional and Intelligence environment can leads towards the better humanistic environment and resultantly increase the employees performance and satisfaction. (Saleh, Yaacob \& Rosli, 2015; Duy, Thanh, Oanh, Tam, \& Vu, 2015), Available limited studies also argued that thinking, soul, wisdom and emotions have effects on employee's performance. (George 2006, king 2008).

\section{Linking IQ EQ SQ and Religion with Employees Performance}

Joshanloo (2010) articulated that IQ, EQ and SQ are not linked with religion, contrarily, Gillian (2012) takes the opposite stance finding the linkages of IQ, EQ and SQ with religion mentions. While linking IQ, EQ and SQ with employee performance, it is noted that IQ helps the employees in reasoning, planning, problem solving, abstract thinking, understanding the idea, and learning and resultantly improve the level of performance (Koohbanani, 2013) While EQ makes the organization's environment satisfying and build optimistic relationship with employees, positively impacting the performance(Bar-on, 2006;Chopra 2010). In addition, if IQ is about thinking and EQ is about feeling, then SQ is about being. SQ is the capacity that allows an employee to live in synch with his/her true self, that silently strengthen the spirit of purity (Mc Mullen (2003) and hence effect the performance level.

IQ, EQ and SQ practices would be more prevalent and acceptable in the Muslim societies if Islamic values and teachings are added. (Osman et al 2013). According to Mohamed et al (2004), organizations may pay a heavy price if they will oversight these quotients.

Based on the literature review, this study proposes the following under-mentioned conceptual framework for Establishing Linkages between Intelligent, Emotional and Spiritual Quotient on Employees Performance in Government Sector of Pakistan. The independent variables, IQ, EQ and SQ are related to dependent variable, employees' performance, whereas religion acts as a moderating variable (Figure 1).

H1 Intelligence Quotient positively effects employee performance.

H2 Emotional Quotient positively effects employee performance.

H3 Spiritual Quotient positively effects employee performance.

$\mathrm{H} 4$ Religion moderates the influence of intelligence quotient, emotional quotient and Spiritual quotient on employee performance.

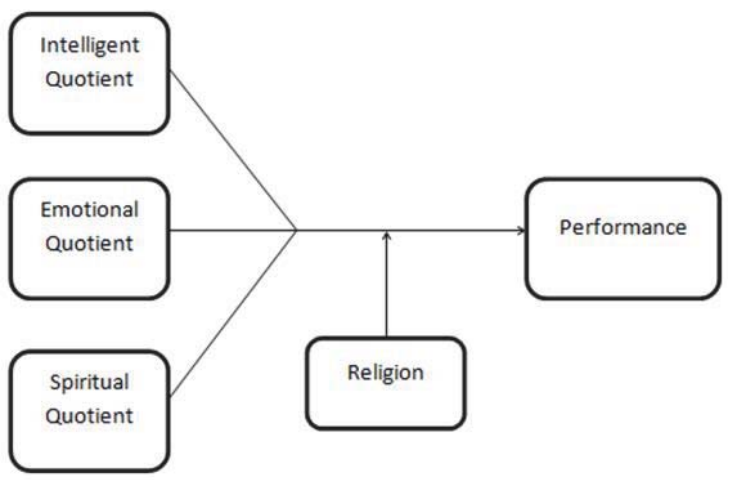

Figure 1: Conceptual Framework

Source: The Author (2015) 
Table No 1: Selected Grades wise respondent

\begin{tabular}{lcccc}
\hline & 1-13 Grade & 14-18 Grade & 19-22 Grade & Total respondents \\
\hline Ministry & 27 & 20 & 8 & 55 \\
Administration & 92 & 23 & 5 & 120 \\
Directorate & 140 & 29 & 3 & 172 \\
\hline Total & $\mathbf{2 5 9}$ & $\mathbf{7 2}$ & $\mathbf{1 6}$ & $\mathbf{3 4 7}$ \\
\hline
\end{tabular}

\section{Methodology}

\subsection{Population and sampling Procedures}

The study used quantitative approach applying survey method based on primary data, gathered from the 33 government departments and 71 directorates through a comprehensive and well designed questionnaire and 42 indicators under categories of Intelligence quotient, emotional quotient, spiritual quotient, religion and performance. Then random sampling technique is applied in stratified sample to dig out the required information for this study.

\subsection{Research Instruments and study measures}

All questions except for respondents' background were based on a five-point scale. The instrument incorporated several established measures. The variables of Intelligence quotient were developed from Adrian Furnham (1999). Emotional quotient scale (EQs) was adopted from Reuven Bar-On (2006). Spiritual Intelligence Self-Report Inventory (SISRI) was used to measure SQ. SISRI was hired from King (2008). For measuring the religion, this research adopted "religiosity personality index" measured by Azimi et-al (2007). Lastly, to measure the employees' performance, 8 items were adopted from Sarmiento et al. (2007).

The research instrument comptised of three sections: Section A aimed to get data regarding IQ, EQ, SQ and religion while Section $B$ gathered data on Employees' performance and section C solicited information regarding the respondent.

\subsection{Cronbach's Alpha Test}

Before putting the data for various analyses, it is worthy to apply Cronbach's alpha to test the reliability of the data. Cronbach's alpha is a measure of internal consistency, that is, how closely related a set of items are as a group. A "high" value of alpha is often used (along with substantive arguments and possibly other statistical measures) as evidence that the items measure an underlying (or latent) construct. Technically speaking, Cronbach's alpha is not a statistical test; it is a coefficient of reliability (or consistency). Cronbach's alpha can be written as a function of the number of test items and the average inter-correlation among the items. Below, for the purpose of the concept, we show the formula for standardized Cronbach's alpha test:

$$
\alpha=\frac{N \cdot \bar{c}}{\bar{v}+(N-1) \cdot \bar{c}}
$$

As far as our data is concerned, It was 0.656 (Table 1) which was quite encouraging figure to put the data for further statistical analysis.

Table 2: Cronbach's Alpha Test

\begin{tabular}{|c|c|}
\hline Cronbach's Alpha & No of Items \\
\hline 0.656 & 42 \\
\hline
\end{tabular}

The value Cronbach's Alpha is greater than 0.5 which shows internal consistency in all 42 items is quite encouraging. Cronbach's alpha was separately applied on 5 variable with is motioned in Table no 3. 
Table 3: Cronbach's Alpha for each variable

\begin{tabular}{|l|c|c|}
\hline Variables & Cronbach'sAlpha & No of Items \\
\hline Intelligence Quotient & 0.62 & 4 \\
\hline Emotional Quotient & 0.57 & 6 \\
\hline Spiritual quotient & 0.67 & 12 \\
\hline Religion & 0.59 & 12 \\
\hline Performance & 0.83 & 8 \\
\hline
\end{tabular}

\section{Results}

\subsection{Demographic profile of the respondents}

There were 347 sets of questionnaires completed for this study. This means, there are 347 employees, $82.70 \%$ are males and $17.30 \%$ are females, about $24.49 \%$ were up to 30 years old employees, $27.67 \%$ were 31 to 40 years old employees, $30.55 \%$ were 41 to 50 years old employees and $17.29 \%$ were 51 to 60 years old employees. In total $1.72 \%$ of the respondents possessed secondary high school, $48.13 \%$ possessed bachelor's degree, $49.57 \%$ had master degree and $0.58 \%$ have completed doctoral degree. Overall, there were $74.64 \%$ of the respondents who served in 1-13 grades, $20.75 \%$ were in $14-18$ grades and the remaining $4.61 \%$ was in $19-22$ grades in their respective organization. 12.68 respondents worked for less than three years, $19.31 \%$ respondents of total service length is 4 to 5 years, $29.68 \%$ of respondents have 6 to 10 years of experience, 31.12\% respondent have 11 to 15 years of experience and $7.21 \%$ of the total respondents had experience of more than 16 years. In term of place of jobs, $15.85 \%$ of the respondents worked in Ministry, 34.58\% have work in Administration; the remaining 49.57\% work in Directorate (Table 3).

\subsection{Factor analysis}

Factor analysis was conducted to identify whether the interdependent questions refer specifically to IQ, EQ, SQ and performance groups, respectively. If the question is loaded correctly with the corresponding factor then the questions were set appropriately. As can be seen in Table No 4, all IQ, EQ, SQ, religion and performance items are loaded correctly to their corresponding factors. The Kaiser-Mayer-Olkin (KMO) measure of sampling adequacy value is 0.866 and the $\mathrm{x}^{2}$ approximation for Bartlett's test of sphericity significant at P0.000. These two statistics confirm that no variable should be dropped and all are suitable for the factor analysis.

\subsection{SEM}

Using data from overall employees, it is confirmed statically that IQ, EQ, and SQ have a significant positive relationship with work performance. Since the coefficient of SQ is higher than EQ and IQ, it can be understood that better spiritual condition influences employees more to achieve a better performance compared with performance in ritual activity. In other words, believing that one is always monitored by God (ihsan) is giving a better impact than just performing ritual activity of a religion. The model developed could explain approximately 28.0 per cent of variation in performance. Model fit indices like $\mathrm{GFI}, \mathrm{CFI}$, and RMSEA all confirm that the model developed is able to fit the data. The next step is running the SEM analysis for 1-13 grade, 14-18 grade and 19-22 grade separately to find out whether religion has a moderating effect upon employee performance. Figure 3 shows the SEM results 1-13 grade of employees. The coefficients of spiritual quotient increase significantly from 0.28 to 0.32 and intelligence quotient and emotional quotient are decries from 0.30 to 0.14 and 0.26 to 0.16 . In addition, the coefficient of determination also improves from 0.28 to 0.31 , which means that 31.0 per cent of variance in dependent variable can be explained by the model developed.

The results on 14 to 18 grade employees; data show the coefficients of IQ, EQ, SQ are decrees from all 1-22 grade employees and that's negativity effect dependant variable which is decrease 0.28 to 0.24 (see figure $2 \& 4$ ) but 113 grade employees IQ, EQ level is less than 14-18 grade employees but SQ is decrese from 32 to18, The dependant variable (performance) also decrease from 31 to 24 , means SQ have more significant effect on performance either then IQ \& EQ, However, the results on 19 to 22 grade employees' data show the opposite. SQ coefficients decrease significantly from 0.28 to 0.14 . In fact, the coefficient of IQ, EQ increase 0.30 to 0.32 and 0.26 to 0.28 . Furthermore, according to its new R2, the model now can only explain $19 \%$ of variation in dependent variable (see Figure 5). These 
confirm the hypothesis mentioned earlier that religion is a moderating variable for employees' job performance.

Table No 3: Demographic profile of the respondents

\begin{tabular}{lcc}
\hline Demographic factor & Total & $\%$ \\
\hline & Gender & \\
Male & 287 & 82.70 \\
Female & 60 & 17.30 \\
Up to 30 years old & Age & 24.49 \\
31-40 years old & 85 & 27.67 \\
41-50 years old & 96 & 30.55 \\
51-60 years old & 106 & 17.29 \\
60 years and above & 60 & \\
Secondary high school & Level of education \\
Bachelor's degree & 6 & 1.72 \\
Master degree & 167 & 48.13 \\
Doctoral degree & 172 & 49.57 \\
& 2 & 0.58 \\
1-13 Grade & & \\
14-18 Grade & Current position & 74.64 \\
19-22 Grade & 259 & 20.75 \\
& 72 & 4.61 \\
& 16 & \\
Less than or equal to 3 years & & 12.68 \\
4-5 years & Total Service length \\
6-10 years & 44 & 19.31 \\
11-15 years & 67 & 29.68 \\
16 years and above & 103 & 31.12 \\
& 108 & 7.21 \\
& 25 & \\
Less than or equal to 3 years & & \\
4-5 years & Current service length & \\
6-10 years & 19 & 5.48 \\
11-15 years & 97 & 27.95 \\
16 years and above & 124 & 35.74 \\
& 71 & 10.46 \\
Ministry & 36 & 34.58 \\
Administration & & 49.57 \\
Directorate & Employees \\
& 55 & \\
& 120 & \\
& 172 & \\
& & \\
& & \\
& & \\
& &
\end{tabular}

Table No 4: Factor analysis result

\begin{tabular}{|c|c|c|c|}
\hline & \multicolumn{3}{|c|}{ Intelligence Quotient Emotional Quotient Spiritual Quotient Religion Performance } \\
\hline IQ2 & 0.559 & & \\
\hline IQ4 & 0.645 & & \\
\hline EQ5 & & & \\
\hline EQ7 & & & \\
\hline EQ10 & & 0.654 & \\
\hline SQ11 & & 0.507 & 0.648 \\
\hline SQ12 & & & 0.686 \\
\hline SQ14 & & & 0.655 \\
\hline SQ15 & & & 0.555 \\
\hline SQ16 & & & 0.516 \\
\hline SQ19 & & & 0.634 \\
\hline
\end{tabular}




\begin{tabular}{|c|c|c|c|}
\hline SQ21 & 0.547 & & \\
\hline SQ22 & 0.604 & & \\
\hline REL23 & & 0.541 & \\
\hline REL24 & & 0.641 & \\
\hline REL25 & & 0.587 & \\
\hline REL27 & & 0.692 & \\
\hline REL28 & & 0.518 & \\
\hline REL30 & & 0.532 & \\
\hline REL31 & & 0.709 & \\
\hline REL32 & & 0.519 & \\
\hline PER35 & & & 0.745 \\
\hline PER37 & & & 0.582 \\
\hline PER38 & & & 0.529 \\
\hline PER40 & & & 0.625 \\
\hline PER41 & & & 0.701 \\
\hline Per42 & & & 0.654 \\
\hline
\end{tabular}

Notes: $K M O=0.866 ; x^{2}$ approximatlely for Bartlett's test $=24,419.9$ ( $p$-value $\left.=0.000\right)$

\section{Discussion and Conclusion}

The purpose of the study was to examine the influence of IQ, EQ and SQ on employee's performance in organization. The result from SEM analysis showed that IQ, EQ and SQ have a significant positive relation with job performance for all employees (i.e. 1-13 grade, 14-18 grade, 19 to 22 grade), and religion moderates the relationships.

This finding is consistent with previous studies. For instance, Osman et al, (2013), found religiosity and spirituality have positive effect on performance, while, Adrian Furnham (1999) and Bar-on (2006) reported that the employees in his study IQ and EQ have positive effect employees. Zohar \& Marshal (2000), and King (2008) also found SQ have positive effect on employees, Another finding of the present study is that the coefficient of SQ is more effective then IQ and EQ on employees performance, which indicated that better SQ in employees more to show better performance compared with IQ and EQ. it is found that religion is a moderating variable for employees performance. This result supports previous studies that there is a significant positive relationship between SQ with religion (Kwilecki 2009) and in the workplace (George 2006) in the leadership (Hyson 2013),

This particular study has provided a new input to knowledge in the field of IQ, EQ and SQ. it has extended the knowledge of SQ at workplace by not only confirming the previous studies but also by confirming that SQ is more significant than IQ and EQ in influencing employees performance.

The limitation of this study is that to examined IQ, EQ and SQ at the grade level, not at organizational level. Another limitation is that this study research did not analyse all of the factor analysis results. Different measurements of IQ , EQ and SQ may be applied, Hopefully, findings from this study will trigger more research intrersts in future among the scholars of relevant fields of study

\section{Acknowledgment}

The Authors thanks for the support provided by Research Creativity and Management Office (RCMO) and USM Fellowship in conducting this research.

\section{References}

Azimi, H., Turiman, S., Sidek, N., Rumaya, J., Abdul, L., Jamilah, M., Khiarul, A., Mastor, M. and Hasnan, K. (2007), muslim Religiosity Personality Assessment: Prototype for Nation Building, Institute of social science studies university putra Malaysia

Baron, R. M. (2006). The Bar-On model of emotional-social intelligence (ESI).Psicothema, 18(1), 13-25.

Bell, I. B. G. (2014). How talent intelligent is your organization?: An interview with Nik Kinley and Shlomo Ben-Hur, authors of Talent Intelligence: What You Need to Know to Identify and Measure Talent. Development and Learning in Organizations, 28(1), 29-31.

Brannan, M. J., Parsons, E., \& Priola, V. (2015). Brands at Work: The Search for Meaning in Mundane Work. Organization Studies, 36(1), 29-53.

Chopra, P. K., \& Kanji, G. K. (2010). Emotional intelligence: A catalyst for inspirational leadership and management excellence. Total Quality Management, 21(10), 971-1004.

Duy, N. K., Thanh, P. T., Oanh, N. T. H., Tam, N. D., \& Vu, T. T. (2015). Impact Evaluation of Training on Firms' Performance: The Case of the Small and Medium Enterprises in Vietnam. Mediterranean Journal of Social Sciences,6(2), 399. 
Feldman, Herbert. "Pakistan--1973." Asian Survey (1974): 136-142.

Furnham, A., Fong, G., \& Martin, N. (1999). Sex and cross-cultural differences in the estimated multi-faceted intelligence quotient score for self, parents and siblings. Personality and Individual Differences, 26(di), 1025-1034.

Garcia-Zamor, J.C. (2003), "Workplace spirituality and organizational performance", Public Administration Review, Vol. 63 No. 3 , pp. 355-363

George , Mike . (2006). Practical application of spiritual intelligence in the workplace. Human Resource Management International Digest, 14, 3-5.

Hyson, P. (2013). The spirited leader: the potential of spiritual intelligence to improve leadership. The International Journal of Leadership in Public Services, 9(3/4), 109-115.

Joshanloo, M. (2010). Investigation of the Contribution of Spirituality and Religiousness to Hedonic and Eudaimonic Well-Being in Iranian Young Adults. Journal of Happiness Studies, 12(6), 915-930.

Karakas, F. (2010). Spirituality and performance in organizations: A literature review. Journal of Business Ethics, 94, 89-106.

King, D. B. (2008). rethinking claims of SI a definition, Model, and measure. Thesis, 12, 23-56.

Kilic, K., Tavacioglu, L., \& Bolat, P. (2013). Influence of Emotional Intelligence on the Work Performance of Seafarers. Marine Navigation and Safety of Sea Transportation: STCW, Maritime Education and Training (MET), Human Resources and Crew Manning, Maritime Policy, Logistics and Economic Matters, 169.

Klerk, J. J. De. (2005). Spirituality, Meaning in Life, and Work Wellness: a Research Agenda. International Journal of Organizational Analysis, 13, 64-68.

Koohbanani, S. E., Dastjerdi, R., Vahidi, T., \& Far, M.-H. G. (2013). The Relationship Between Spiritual Intelligence and Emotional Intelligence with Life Satisfaction Among Birjand Gifted Female High School Students. Procedia - Social and Behavioral Sciences, 84, 314-320.

McMullen, B. (2003). Emotional intelligence. BMJ, 326(7381), 19-19.

Mishra, P., \& Vashist, K. A Review Study Of Spiritual Intelligence, Stress And Well-Being Of Adolescents In 21 St Century.

Mohamed, A., Wisnieski, J., Askar, M. and Syed, I. (2004), "Towards a theory of spirituality in the workplace", Competitive Review: An International Business Journal of Global Competitiveness, Vol. 14 Nos 1-2, pp. 102-107.

Noronha, K. J. (2015). Impact of Religion and Spirituality on Older Adulthood. Journal of Religion, Spirituality \& Aging, 27(1), 16-33.

Osman-Gani, Aa. M. (2013). Establishing linkages between religiosity and spirituality on employee performance. Employee Relations, $35,360-376$.

Rafique, Z., \& Anwar, M. A. (2014). Insurgency in Afghanistan: implications for Pakistan's internal and external security. Defense \& Security Analysis, 30(3), 266-282.

Reid, G. a. (2012). Spirituality and End of Life Issues: A Review. Journal of Religion, Spirituality \& Aging, 24(September 2014), 120-130.

Sarmiento, R., Beale, J., \& Knowles, G. (2007). Determinants of performance amongst shop-floor employees: A preliminary investigation. Management Research News, 30(12), 915-927.

Saleh, N. S., Yaacob, H. F., \& bin Rosli, M. S. (2015). Critical Review: Assessing and Seeking the Intricacy or Discrepancy of Ulrich Model Transforming Paradigm in Organization Human Resource. Mediterranean Journal of Social Sciences, 6(2), 324.

Sharabi, M. (2009). Work values, employment and ethnicity: Jewish and Muslim academic graduates in Israel. Cross Cultural Management: An International Journal, 16, 398-409.

Upadhyay, S., Upadhyay, N., \& Pinto, S. (2015). Spiritual Intelligence and Organisational Effectiveness Ecosystem. In International Conference on Technology and Business Management March (Vol. 23, p. 25).

Zohar, D., Marshall, I. N., \& Marshall, I. (2000). SQ: Connecting with our spiritual intelligence. Bloomsbury Publishing USA. 